\title{
SigNIFICAÇÃO RELIGIOSA DO SOFRIMENTO E POSIÇÃO PSICOLÓGICA NA FÉ ${ }^{1}$
}

\author{
Jean-Marie Jaspard \\ Université Catholique de Louvain-la-Neuve
}

\begin{abstract}
Estuda-se o vínculo psicológico entre a experiência existencial do sofrimento e a posição do sujeito em relação à fé religiosa. A investigação foi realizada com 80 enfermeiros, de ambos os sexos, com várias modalidades de adesão ao cristianismo. A hipótese foi a de que essas pessoas são obrigadas a estruturar para si mesmas uma atitude mais ou menos estável, consciente ou refletida, em relação ao sofrimento. Foi construído um questionário com uma pergunta acerca do sofrimento, (dimensões, apreensão psicológica, sentido), uma pergunta acerca da posição religiosa (central ou periférica, segura ou hesitante) e uma pergunta acerca da atribuição de conotações religiosas ao sofrimento. Os resultados não permitem enunciar uma teoria unívoca da relação entre religião e sofrimento, mas a existência de configurações singulares mais ou menos estáveis e evolutivas, segundo a orientação básica da atitude religiosa, o contexto meramente humano do sofrimento e a contextualização religiosa do sofrimento.
\end{abstract}

Descritores: Sofrimento. Psicologia e religião.

Dretendo relatar uma pesquisa que vários pesquisadores do Centro de Psicologia da Religião de Louvain-La-Neuve desenvolveram, sob minha direção, há cerca de 10 anos. Trata-se de uma pesquisa relativa à experi-

1 Conferência proferida no Instituto de Psicologia da Universidade de São Paulo e no Programa de Pós-Graduação em Psicologia Clínica da Pontifícia Universidade Católica de São Paulo, nos dias 10 e 12/09/2002, no quadro do $4^{\circ}$ Seminário Psicologia e Senso Religioso, "Processos psicológicos na representação religiosa", com apoio da FAPESP. Tradução de Geraldo José de Paiva e Marília Ancona-Lopez. 
ência do sofrimento e, mais particularmente, aos aspectos psicológicos que se manifestam quando as pessoas se colocam na perspectiva de associar a ele significações religiosas e, até, de integrá-lo num encaminhamento religioso. Na realidade, a questão geral que nos colocávamos era a de saber qual o vínculo psicológico que pode ser estabelecido entre, de um lado, uma experiência existencial tal como o sofrimento e, de outro, a experiência religiosa ou a posição das pessoas na fé religiosa. Encontram-se, com efeito, na literatura e na história, relatos de posições muito variadas a esse respeito. Pensese na história de Jó, que se debatia crucialmente com o paradoxo que vivia em seus sofrimentos, suas perdas, seus lutos e sua representação de Deus. Pense-se na teologia do poder redentor da paixão de Jesus, veiculada ao longo dos séculos. Pense-se em todos os doentes, levados em peregrinação. Pense-se na devoção brasileira de Nossa Senhora das Dores. Pense-se nos contemporâneos que se negam a crer na existência de Deus por causa da existência do mal. Pense-se na convicção de Freud de que os homens inventaram a religião para se dar uma resposta, "ilusória", diz ele, às questões insolúveis do sofrimento e da morte. Pense-se em um filósofo como Sören Kierkegaard etc. Em suma, será psicologicamente possível articular essa experiência humana com uma fé religiosa? e caso seja possível, de que maneira? Que configurações da atitude religiosa facilitam ou dificultam essa articulação? É isso que procuramos esclarecer.

Depois de várias pequenas tentativas, decidimos realizar uma investigação com pessoas cuja profissão é cuidar de doentes: enfermeiros e enfermeiras. São profissionais em contato cotidiano e prolongado com pessoas que sofrem de doenças diversas, mas também com os múltiplos tipos de sofrimentos morais e psicológicos que se enxertam praticamente sempre nos sofrimentos físicos. Nossa hipótese era a de que essas pessoas são obrigadas a estruturar para si mesmas uma atitude mais ou menos estável, e mais ou menos consciente ou refletida, em relação ao sofrimento. À força de conviver com o sofrimento, esses profissionais são levados, por um lado, a captar as diversas facetas sensíveis dessa experiência para aqueles e aquelas que a vivem e, por outro, a tomar distância para lhe dar um sentido ou orientá-la na perspectiva de um sentido. Além disso, pensávamos que enfermeiros e 
enfermeiras que aderem à fé cristã poderia m compartilhar conosco a maneira como essa experiência humana do sofrimento encontra lugar em seu próprio debate religioso.

Uma vez colocada essa dupla hipótese, quase como um postulado, elaboramos um dispositivo de pesquisa exploratória que se adaptasse a nosso público-alvo e fizesse aparecer os dois elementos investigados: experiência do sofrimento e atitude religiosa, e permitisse ver como esses elementos se articulam entre si na vida de nossos sujeitos. Com esse objetivo, construímos um longo questionário (13 páginas, com 18 questões ou subquestionários, 5 questões abertas e 13 questionários de múltipla escolha ou com escalas Likert). Esse questionário comporta várias partes organizadas de maneira progressiva: uma pergunta acerca do sofrimento, suas dimensões, sua apreensão psicológica, o sentido que lhe é atribuído enquanto sofrime nto; em seguida, uma pergunta sobre a posição religiosa mais ou menos central ou periférica, mais ou menos segura ou hesitante; enfim, uma pergunta sobre a atribuição possível de conotações religiosas ao sofrimento: e aqui, referências religiosas diversas foram apresentadas aos sujeitos para ver quais repercutiam em sua sensibilidade e quais abriam ou fechavam uma porta para a atribuição de um sentido ou de um vínculo religioso com o sofrimento.

Uma palavra sobre a amostra. Houve várias amostras e apresento brevemente aquela cujos resultados serão expostos. Por várias razões, mantivemos exclusivamente pessoas que se diziam cristãs e crentes; mas, como veremos adiante, há muitas posições diferentes possíveis para essa atitude religiosa; e são essas múltiplas "posições" que nos servirão como elementos diferenciadores.

A amostra compõe-se de 80 sujeitos, enfermeiros de profissão, na maioria mulheres. Os sujeitos foram distribuídos segundo o grau de prática e de crença religiosa. Todos se dizem crentes, mas, entre eles, alguns são crentes convictos, outros habitados por dúvidas mais ou menos importantes; alguns têm uma prática religiosa regular, outros uma prática ocasional (etapas da vida, acontecimentos familiares), outros ainda não praticam mais. Para diferenciar o grau de crença, com o auxílio de duas perguntas do ques- 
tionário, chegamos a distinguir subgrupos que fazem aparecer matizes interessantes da estrutura da atitude religiosa: 1) o fato de estar persuadido de que a fé pessoal não vai mudar no futuro ou de pensar que essa fé poderia evoluir; 2) o fato de ter feito ao menos uma vez na vida a experiência da proximidade de Deus ou de não ter tido essa experiência. Esse primeiro inventário realizado na amostra permitiu-nos compor:

a) quatro grandes grupos de pessoas

segundo o grau de certeza na fé:

Oscrentes convictos $(n=41)$

Os crentes duvidantes $(\mathrm{n}=39)$

segundo o grau de prática religiosa:

Os praticantes regulares $(n=41)$

Os praticantes ocasionais $(\mathrm{n}=27)$

b) seis subgrupos, segundo esses matizes nos graus de fé ou de prática:

Os crentes convictos, cuja fé não vai mudar $(\mathrm{n}=17)$

Os crentes convictos, cuja fé poderia evoluir $(n=16)$

Os crentes duvidantes praticantes regulares $(n=13)$

Os crentes duvidantes praticantes ocasionais $(n=17)$

Os crentes duvidantes que experimentaram a proximidade de Deus $(\mathrm{n}=15)$

Os crentes duvidantes que não tiveram essa experiência $(n=17)$.

Para terminar a apresentação da amostra, vou referir-me a uma observação a partir da qual nos demos conta de mais uma gradação nas nuances dessas posições religiosas. Entre os 13 subquestionários, havia o de Batson e Ventis, relativo às orientações da atitude religiosa: intrínseca, extrínseca e de busca (quest). A esse respeito, eu, pessoalmente, continuo pensando que toda pessoa vive sua fé com as três dimensões (e não apenas com uma). A diferença entre os indivíduos encontra-se no grau de presença de cada dimensão na atitude. Para nossa amostra, constatamos que os 4 grandes grupos e os 6 subgrupos se distribuem numa ordem bastante significativa, quando organizados na ordem decrescente dos resultados médios da escala "intrín- 
seca". Vê-se que os resultados das escalas "busca" e "extrínseca" criam uma forma de modulação que dá uma configuração específica de cada grupo e subgr upo, de sorte que eles aparecem mais ou menos próximos ou diferentes uns dos outros.

Assim, vemos, à extrema esquerda, os grupos de praticantes regulares (REG) e de crentes convictos (CC), cujos representantes mais "puros" são os que acreditam que sua crença não sofrerá mudança no futuro (CCch-); eles se caracterizam por uma posição na qual o intrínseco domina claramente a busca e o extrínseco. $\mathrm{Na}$ extrema direita, encontramos os dois grupos de praticantes ocasionais (OCC) e crentes duvidantes (CD), particularmente representados pelos praticantes ocasionais (CDocc) e pelos que dizem não ter sentido com freqüência a presença de Deus em sua vida (CDexp-); aqui, a posição "busca" é dominante e a posição extrínseca se aproxima sensivelmente da posição intrínseca. No meio, encontramos os três últimos subgrupos bastante próximos uns dos outros: os que pensam que sua conviç̧ão religiosa poderá mudar no decorrer da vida $(\mathrm{CCch}+)$, os praticantes regulares (CDreg) e os que dizem ter sentido freqüentemente a presença de Deus na vida $(\mathrm{CDexp}+)$; o parentesco entre esses três subgrupos se encontra numa coexistência à parte quase igual das posições "intrínseca" e "busca", e numa presença muito menor da posição "extrínseca".

Se traduzirmos essa observação em linguagem corrente, observamos um subgrupo de crentes convictos e estáveis, que dão grande importância a sua relação com um Deus em quem têm plena confiança; a seguir, três subgrupos de crentes mais ou menos em busca, com matizes próprios a cada grupo; eles estão ou abertos à mudança em sua fé, ou então duvidam e questionam; geralmente são praticantes regulares ou dão testemunho de uma

$2 \mathrm{CC}-\mathrm{CD}=$ Crentes Convictos-Crentes Duvidantes; REG-OCC $=$ Praticantes regulares e Praticantes ocasionais; $\mathrm{CCch}--\mathrm{CCch}+=\mathrm{Crentes}$ que não esperam ou que esperam mudança religiosa na vida; $\mathrm{CDreg}-\mathrm{Cdocc}=$ Crentes duvidantes praticantes regulares e Crentes duvidantes praticantes ocasionais; CDexp $+-\mathrm{CDexp}-=$ Crentes duvidantes que dizem ter ou não ter freqüente experiência de Deus na vida; CCch+ - Cdreg =Crentes convictos que admitem mudança futura e Crentes duvidantes praticantes regulares. 
experiência religiosa positiva; enfim, temos dois subgrupos de crentes mais desligados, praticantes irregulares ou sem experiência religiosa positiva. Veremos como cada um desses grupos organiza seu vínculo entre sofrime nto e religião de maneira diferenciada.

Mas antes de analisar a relação religião-sofrimento em seu conteúdo, proponho que comecemos por olhar os resultados de algumas comparações que fizemos entre as respostas dos diferentes subgrupos, quando as perguntas faziam falar do sofrimento sem evocar o contexto religioso e quando as perguntas evocavam explicitamente referências religiosas. $\mathrm{O}$ resultado das comparações, independentemente dos conteúdos propriamente ditos, é uma espécie de aperitivo para o que seguirá.

Para cada item do questionário, calculamos o resultado médio por grupo e por subgrupo. Em seguida, as diferenças de médias foram testadas com a ferramenta adequada (segundo o tipo de itens): $t$ de Student ou tau de Kendall. Para cada item, foram feitas duas comparações entre os grupos CC CD e REG - OCC, e quatro comparações entre os subgrupos: CCch-CCch+; CDreg - CDocc; CDexp+ - CDexp-; CCch+ - CDreg. Portanto, ao todo, seis comparações.

A seguir, serão apresentados os resultados obtidos.

1. Quanto ao sofrimento no contexto humano natural:

- 37 itens; 222 comparações

- 10 diferenças significativas observadas (4,5\% das comparações)

- 212 casos de semelhança observados

As poucas diferenças observadas são, às vezes, a favor das pessoas mais crentes, às vezes, a favor das pessoas menos crentes.

2. Quanto ao sofrimento no contexto religioso:

- 27 itens; 162 comparações

- 74 diferenças significativas observadas (45,7\% das comparações)

- 88 casos de semelhança observados 
Notamos que 71 das diferenças observadas são a favor do primeiro grupo ou subgrupo, isto é, das pessoas mais crentes. Os grupos se diferenciam muito; entre os subgrupos, a experiência da proximidade de Deus (CDexp+) é a mais diferenciadora.

Mas essa assimetria observada conduz, também, a um comentário de ordem metodológica quanto à construção do questionário. Isso mostra, com efeito, que os itens formulados no contexto religioso entram em consonância positiva com a orientação de fé mais do que com a orientação de não fé. Voltaremos ao assunto mais tarde.

\section{A conotação semântica da palavra "sofrimento"}

A questão levantada (bem no começo do questionário) era: "Quando vocês ouvem a palavra "sofrimento", quais são as primeiras palavras que vêm a sua mente? Poderia citar 5 delas?"

Foram recolhidas mais ou menos 400 palavras ( 80 x 5); cerca de 200 palavras diferentes, portanto, uma grande dispersão, mas muitos sinônimos; muito poucas palavras com conotação religiosa. ${ }^{3}$ Verificoutse difícil e pouco rentável operar uma classificação. Decidimos, por isso, proceder de modo diferente, referindo-nos a um "dicionário semântico psicológico", construído por um colega da Faculdade, em Louvain-La-Neuve. É um dicionário que atribui a todas as palavras correntes da língua francesa um índice que representa (numa escala de 1 a 7) a carga de evocação da palavra em diversos estados psicológicos (por exemplo, a palavra "medo" ou "ternura" tem forte carga de evocação da emocionalidade; "agir" conota muito fortemente a ativação da pessoa; "julgar" conota a avaliação etc.). Esses índices do questionário foram calculados, fazendo-se pesquisas em grandes amostras representativas das populações de língua inglesa e de língua francesa.

3 O mesmo aconteceu numa aplicação do questionário numa congregação de religiosas. 
Mantivemos, para as associações com nossa palavra "sofrimento", os índices relativos, exatamente, a sua capacidade de conotar a emocionalidade (teor afetivo), a ativação do eu (estimulação para agir) e a avaliação (agradável vs. desagradável). O quadro seguinte mostra os resultados dessa operação.

Podemos tirar desses resultados algumas lições. Observamos, por exemplo, que comparativamente às médias das palavras do dicionário ordinário, a palavra "sofrimento" tem uma carga significativamente muito alta de "emocionalidade" (ela evoca principalmente emoções negativas, como a angústia); a palavra é, aliás, particularmente "avaliada" do lado "desagradável", penoso de ver; é percebida como medianamente "ativadora" (evoca, princ ipalmente, a luta para enfrentar, o coping).

Se compararmos nossos grupos, aparecem algumas tendências sem que as diferenças observadas sejam estatisticamente significativas:

- as emoções negativas parecem despertar mais nas pessoas menos religiosas ou duvidantes e menos nos crentes mais estáveis na fé;

- quanto mais o sofrimento evoca reações de ativação, menos parece vivido como desagradável, e vice-versa.

Aproximemo-nos, agora, progressivamente, dos resultados cada vez mais interessantes, que vão se somar para produzir uma espécie de geografia das atitudes e das configurações que caracterizam nossos grupos e subgrupos.

Modificações nas representações de si mesmo, dos outros, do mundo e de Deus.

A questão era saber em que medida o confronto com o sofrimento (especialmente no exercício profissional) leva a uma modificação da imagem que a pessoa tem de si, do mundo, dos outros, de Deus e do sentido da vida.

As respostas se distribuem no quadro seguinte. Constatamos, como esperado, que é a imagem dos outros que muda mais (sem dúvida, ela se 
modifica à medida que vai aparecendo o sofrimento, no doente cuidado pelo profissional). Em seguida, é o sentido da vida que é abalado, juntamente com a imagem do mundo. O que parece menos modificado é a imagem de Deus. Quanto à imagem de si mesmo, todas as percepções se apresentam numa medida equivalente.

Quando comparamos os grupos, vemos que os que duvidam ressentem uma modificação da imagem de si e da imagem dos outros mais do que os que se sentem seguros na fé. A diferença mais acentuada situa-se entre os CDreg (75\%) e os CDocc(35\%).

Calculamos, também, as correlações dos resultados entre os diferentes objetos de representação, no sentido de responder à questão: que imagens se modificam juntas?

O quadro mostra claramente que todas as correlações são significativas; tudo se correlaciona um pouco com tudo; isso significa que existe um fator pessoal importante: em cada item, algumas pessoas fazem correlações altas, ao passo que outros fazem correlações baixas. Mas três correlações são nitidamente mais significativas que as outras e, por isso, indicadoras de alguma coisa:

- quando a imagem de si se modifica, também se modifica o sentido da vida $(, 41)$;

- a imagem dos outros e a imagem do mundo se modificam conjuntamente (,59);

- a imagem de Deus e do sentido da vida também se modificam conjuntamente (,39).

Poder-se-ia, pois, levantar a hipótese de que, se não há relação direta entre a imagem de si e a imagem de Deus, o sentido da vida tem algo a ver com as duas imagens e pode tornar-se um elemento de junção (uma forma de prisma) que se alimenta em duas fontes (si mesmo e/ou Deus).

4 Remetemos o leitor à nota 2, para esclarecimento dessas abreviações. 


\section{Atribuição de responsabilidade pelo sofrimento}

A questão procurava conhecer a fonte à qual se atribui uma parte da responsabilidade pelo sofrimento que encontramos à nossa volta: à própria pessoa, aos outros, ao acaso, a Deus, às leis da natureza.

O quadro mostra claramente várias coisas. A primeira é que a responsabilidade pelo sofrimento é nitidamente mais atribuída a fontes impessoais do que a vontades pessoais. As leis da natureza constituem o primeiro fato; $\mathrm{o}$ sofrimento é, de alguma maneira, co-natural a elas, ao menos parcialmente. $\mathrm{O}$ acaso, também, é muito freqüentemente incriminado, mas com mais hesitação. Em seguida, vêm os outros, antes da própria pessoa (não perdemos os hábitos contraídos na primeira infância!). Enfim, ao contrário do que se ouve muitas vezes nas recriminações segundo o modelo de Jó: "que é que pude fazer ao bom Deus para que isso me aconteça?", nossas enfermeiras são muito reticentes em atribuir uma responsabilidade a Deus pelo sofrimento que encontram a seu redor.

Mas é aqui que aparecem diferenças nos grupos:

- os CC são muito mais categóricos do que os CD em dizer que Deus não é responsável;

- são os Ccch+ os mais categóricos em desculpar a Deus;

- eles o são muito mais que os CDreg; é, aliás, entre os últimos que se encontram os poucos que estimam que Deus é responsável. Nisso eles se diferenciam claramente dos CDocc. Vamos ver, pouco a pouco, que os CDreg têm a posição mais conflitante com Deus a respeito do sofrimento; mas deixamos que ainda se acumulem os indicadores;

- nota-se, ainda, que os CC são claramente mais numerosos (20\%) que os $\mathrm{CD}(8 \%)$, na recusa em atribuir a responsabilidade pelos sofrimentos às leis da natureza; adivinha-se que isso se relaciona a uma dependência que eles reconhecem entre essas leis da natureza e Deus criador, origem delas.

A esse pequeno panorama, podemos articular o do quadro de correlações seguinte: 
- constata-se que "leis da natureza" e "acaso" mantêm alta correlação, como se um fizesse um pouco parte do outro;

- do mesmo modo, leis da natureza e Deus têm correlação quase significativa, o que confirma o que acabamos de dizer a esse respeito;

- de outra parte, a atribuição da causa do sofrimento conjuntamente à própria pessoa e aos outros parece considerada pelas pessoas que atribuem uma responsabilidade personalizada ao sofrimento;

- enfim, vê-se claramente que a atribuição à própria pessoa ou às leis da natureza são inteiramente incompatíveis; quando é uma, não é a outra, e vice-versa.

\section{Ajuda recebida para enfrentar o sofrimento: sua origem}

Neste item, a pergunta foi a seguinte: em sua confrontação com o sofrimento, em que medida você se sente ajudado(a), apoiado(a) por sua família, seus amigos; seus colegas, sua equipe de trabalho; sua paróquia, comunidade religiosa; um padre, um capelão; suas convicções religiosas; a oração; outra coisa...?

Os resultados foram os seguintes:

- a ajuda e o apoio são encontrados maciçamente na família e com os amigos e, também, em medida menor, com os colegas e no local de trabalho dessas enfermeiras (portanto, no grupo microssocial da vida cotidiana). Aqui, não se encontra diferença entre nossos grupos e subgrupos;

- em segundo lugar, é o campo da fé pessoal (convicções e oração) que oferece um recurso e uma ajuda para afrontar o sofrimento. Mas, aqui, aparecem importantes diferenças entre os grupos e os subgrupos, mais ou menos as mesmas para os dois indicadores:

- os CC e os REG são mais apoiados por sua fé pessoal que os CD e que os OCC; os CCch-, ainda mais que os Ccch+, no que respeita às convicções, assim como os CDreg mais que os Cdocc, no que respeita à oração; 
- o mesmo para os CDexp+ que são mais ajudados por suas convicções e orações do que os CDexp-.

- em terceiro lugar, o campo da comunidade cristã (paróquia, padre) se revela uma fonte de ajuda mais negada que afirmada. Existem, contudo, nítidas diferenças segundos os grupos e subgrupos: as mesmas que acabamos de observar para o campo precedente. Aliás, é lógico que a prática religiosa regular contribua para criar relações que são preciosas quando se encontra a adversidade.

O cálculo das correlações mostra essa configuração dos três registros da ajuda que acabamos de constatar: família, amigos e colegas (,30); convicções religiosas e oração (,72); paróquia e padre (,63).

Mas outras relações aparecem também de maneira significativa: quando designada, a família se correlaciona com todos os outros registros. Para alguns, sobretudo os CCch- e os CDreg, os colegas fazem parte de um ambiente social com paróquia e padres. Da mesma forma, paróquia e padre se correlacionam fortemente com convicções e oração, o que não é de admirar.

\section{O impacto do sofrimento na própria fé}

Neste item, o indivíduo deveria se posicionar em relação à seguinte pergunta: "O contato que tive com o sofrimento":

não teve influência em minha fé

aproximourme de Deus

fez-me duvidar da existência de Deus

me levou a rejeitar a Deus

Constatamos o seguinte:

A rejeição de Deus não foi assinalada por ninguém (trata-se de pessoas que se dizem crentes!).

No total, $40 \%$ não reconhecem nenhuma influência em sua fé; $36 \%$ se aproximaram de Deus; e a dúvida não afetou mais de $24 \%$. 
Mas as diferenças entre grupos e subgrupos foram grandes:

- o efeito principal nos CC é o de aproximar-se de Deus, ao passo que os $\mathrm{CD}$ ou conhecem a dúvida ou não mudam a fé;

- observa-se a mesma diferença entre os REG e os OCC, embora estes sejam ainda mais imprevisíveis no que respeita ao efeito do sofrimento em sua atitude religiosa;

- os CCch- e os CCch+ se distingue m por um fortalecimento quase unânime da fé nos primeiros, mais mitigado nos segundos;

- a dúvida é claramente mais pronunciada nos CDocc do que nos CDreg, tendo mesmo os últimos mais tendência a aproximar-se de Deus do que a duvidar dele;

- enfim, CDexp- e CDexp+ são igualmente levados a duvidar, com os últimos, ainda assim, mais numerosos a aproximar-se de Deus.

Em conclusão, pode-se dizer que a experiência do sofrimento aproxima de Deus os crentes mais convictos (os CCch-), ela não afeta muito a fé atual de numerosos crentes que poderiam considerar pô-la em questão no futuro (os CCch+), tampouco afeta a fé de base de uma boa parte dos que se dizem habitados pela dúvida. A outra parte dos que duvidavam de antemão viram reforçar-se sua dúvida ao encontrar o sofrimento, ao passo que a outra parte dos CCch+ tendeu a aproximar-se de Deus.

As pessoas se voltam para Deus a fim de encontrar um sentido para o sofrimento?

Este tópico se desdobrou em três questões:

- nos primeiros confrontos com o sofrimento, você se voltou para Deus para encontrar um sentido para o sofrimento?

- em que medida isso o ajudou?

- em seu contato atual, você é levado(a) a voltar-se para Deus?

Os resultados se apresentam, pois, em três tempos (quadros). 
a) primeiras confrontações: os resultados se distribuem pela escala de 5 intervalos e os grupos se diferenciam segundo a posição atual da crença; isso dá a entender que a posição atual de nossos sujeitos estava fixada já há muito tempo;

b) a ajuda percebida: a ajuda recebida é percebida na mesma medida que a ajuda solicitada, em todos os grupos e subgrupos. $\mathrm{E}$ as diferenças entre estes se manifestam todas da mesma maneira. São os CCch- e os CDexp+ que se dizem os mais atendidos;

c) atualmente: o recurso a Deus se revela muito mais freqüente atualmente do que na primeira confrontação com o sofrimento. Será isso decorrência do registro profissional, ou do amadurecimento com a idade, ou ainda um efeito da memória, a prazo mais ou menos longo? Difícil de interpretar;

As mesmas diferenças se mantêm entre grupos e entre subgrupos.

Enfim, o cálculo das correlações entre os resultados obtidos das três subperguntas (último quadro) revela uma correlação muito alta, mas com diminuição de uma resposta para outra $(, 72 ;, 52 ;, 39)$.

Pode-se interpretar isso, parece-me, dizendo que a lembrança de ter percebido uma ajuda influencia a repetição do pedido; mas que outros elementos podem estar em jogo, atualmente; por exemplo, o contexto profissional da confrontação com o sofrimento do outro. Pode-se acreditar, também, que a ausência de ajuda percebida por alguns crentes duvidantes interrompeu sua busca religiosa.

\section{Atitudes face ao sofrimento.}

Nosso questionário inclúa, ainda, 39 itens inspirados no trabalho de um pesquisador americano (D.P.Foley), que realizou trabalhos importantes nesse domínio, durante os anos 80 .

Entre os 39 itens, 24 situam o sofrimento no contexto da vida diária, sofrimento da própria pessoa ou de outrem (contexto profano) e 15 itens o contextualizam em referências de conteúdo religioso (contexto religioso). 
Os sujeitos precisavam responder, dizendo se estavam de acordo ou não com o enunciado de um item ou se tinham uma opinião mitigada.

Consideremos os resultados para cada uma das duas séries em separado.

\section{A atitude face ao sofrimento evocado em seu contexto profano.}

Após uma análise do conteúdo dos 24 itens, nós os repartimos em 8 rubricas de sentido. $\mathrm{O}$ quadro apresenta os resultados de todos os sujeitos segundo as rubricas; não considero, aqui, a não ser as porcentagens de aceitação ou de recusa dos itens.

Antes de percorrer os resultados detalhadamente, digo, de imediato, que as comparações foram calculadas entre todos os grupos e subgrupos e que, das 144 comparações efetuadas, somente 56 se revelaram significativas $(3,5 \%)$; estamos no contexto não religioso e constatamos poucas diferenças entre nossos subgrupos.

Evocarei, no momento adequado, as poucas diferenças observadas.

- A tendência é recusar afirmar que o sofrimento não tem sentido; mas, quanto menos se percebe o sentido a lhe dar, mais se levanta a questão desse sentido (principalmente os $\mathrm{CD}$ ) e mais se deseja eliminar o sofrimento.

- O mecanismo de defesa que procura negar o sofrimento é uma reação que as enfermeiras preferem recusar.

- Os sujeitos estão geralmente de acordo para relativizar o sofrimento pessoal, comparando-o com o que acontece a outrem. Encontramos, pois, acordo com uma reação que consiste em alimentar um sentimento otimista, minimizando o sofrimento vivido pessoalmente.

- Ao contrário, aceitar ser simplesmente o joguete da má sorte ou do acaso é claramente menos bem aceito. Podemos ver nisso a recusa de ser obrigado a sofrer passivamente.

- O mesmo acontece com a atitude de resignação diante do que não seria mais que a imposição de uma lei da natureza, mesmo no caso em que 
se aceite que o sofrimento está inscrito nas leis da natureza, o que já não é fácil. Ao contrário, aceitar o sofrimento com um sorriso é considerado como um enfrentamento (coping) positivo, por perto da metade da amostra. Essa valorização do sorriso diante do sofrimento é mais particularmente característica dos REG e dos CCch.

- A inscrição ontológica do sofrimento na condição humana é teoricamente aceita com realismo; mas o fato de que ele aconteça não acarreta automaticamente uma aceitação passiva.

- O fato de poder beneficiar-se de uma contribuição positiva dessa experiência para o crescimento pessoal é considerado como um resultado desejável, até como um coping desejável. Aqui, também, os CCch- se inscrevem mais que os outros nessa perspectiva.

- Enfim, o vínculo possível do sofrimento com uma punição, como efeito de uma justiça imanente ou como uma interpretação algo masoquista, é negado fortemente. Inversamente, os sujeitos aceitam relativamente bem que a existência do sofrimento confirma a crença de que o mundo é injusto. Mas aqui, encontramos 3 das 5 diferenças significativas que assinalava mais acima: elas indicam que as pessoas menos implicadas numa atitude religiosa positiva crêem com mais facilidade que o sofrimento é sinal de um mundo injusto.

\section{A atitude frente ao sofrimento no contexto religioso.}

Aqui, os 15 itens foram repartidos em 5 rubricas, em função do conteúdo. Das 90 comparações calculadas, 41 se mostraram significativas $(45,6 \%)$. Os detalhes serão dados depois de percorrermos os resultados globais por rubrica.

- Resignar-se passivamente ao pensamento de que o sofrimento corresponde a uma vontade de Deus é rejeitado maciçamente, mesmo se alguns podem admitir que Deus tenha controle dos acontecimentos que ocorrem.

- A idéia de interpretar o sofrimento como uma provação querida ou, simplesmente, permitida por Deus para avaliar a consistência da fé ou da 
adesão religiosa, tampouco é apreciada pelas enfermeiras, embora seja rejeitada menos maciçamente. Há mesmo muita reticência em pensar que Deus passaria o tempo acreditando que as pessoas são capazes de suportar o sofrimento.

- Olhar o sofrimento, tentando colocar-se no ponto de vista de Deus, é uma perspectiva que se pode encarar sob certas condições. Que Deus possa ajudar a dar sentido ao sofrimento é algo que se crê de boa vontade; que ele tenha um ponto de vista mais amplo que o ponto de vista da pessoa, talvez, mas não necessariamente; mas que ele queira fazer do sofrimento uma bênção disfarçada, isso não! Seria uma intenção, no mínimo, indecente de sua parte.

- Os sujeitos tendem a ser reticentes, senão negativos, à perspectiva de associar o sofrimento humano ao de Cristo ou a apresentá-lo a Deus como uma oferenda. Eventualmente, alguns aceitariam um pouco mais facilmente, talvez como um apoio, sentir-se próximos do sofrimento de Cristo num momento como esse.

- Pensar que Deus está do lado dos que sofrem, que ele está próximo deles, é bem aceito. Mas acreditar que Deus "com-padece", isto é, "sofre junto", não dá necessariamente mais força para enfrentar o sofrimento.

Se considerarmos, agora, as principais diferenças observadas entre grupos e subgrupos, constatamos que:

- Nenhum grupo ou subgrupo se diferencia em relação à idéia de uma resignação diante de um sofrimento que seria querido por Deus. Essa idéia é rejeitada em bloco.

- Para as outras rubricas, os itens são sempre melhor aceitos pelos CC e pelos REG do que pelos CD e os OCC.

- Os CCh- aceitam melhor que os $\mathrm{CCh}+$ a idéia de que Deus põe à prova, de que ele dá um sentido ao sofrimento e que o sofrimento permite à pessoa associar-se ao sofrimento do Cristo Redentor. 
- Os CDeg aceitam mais do que os CDcc a perspectiva de um Deus que dá sentido ao sofrimento, que crê o ser humano capaz de suportá-lo e de associar esse sofrimento ao de Cristo.

- Os CDexp+ aceitam mais do que os CDexp- a idéia de que o sofrimento pode ser redentor, de que Deus dá sentido ao sofrimento e mesmo se faz próximo dos que sofrem.

\section{Considerações finais}

É tempo de nos perguntarmos o que podemos reter desta pesquisa e de ver o que ela nos ensina. Gostaria de destacar as coisas que apareceram globalmente, mas também de caracterizar a lógica das relações entre sofrimento e fé, no interior dos diferentes subgrupos que foram definidos.

Em primeiro lugar, de um ponto de vista global, proponho reter uma primeira coisa. Observamos uma diferença muito grande na maneira de os sujeitos falarem do sofrimento, quando este é evocado num contexto religioso ou fora do contexto religioso. No contexto religioso, todos os grupos respondem a nossas perguntas de uma maneira diferenciada; no contexto ordinário da vida, todos respondem de maneira bastante semelhante.

Isso significa que o sofrimento é, antes de tudo, uma realidade existencial comum e autônoma no plano "simplesmente humano". Lá, ele é vivido com uma tonalidade emocional bastante carregada e de teor desagradável. Se a própria pessoa sofre, isso não muda quase nada a imagem que ela tem dela; mas se alguma outra pessoa sofre, isso modifica a imagem que se tem dessa pessoa. A experiência do sofrimento pode modificar o sentido que se dá à vida. Se se trata de atribuir uma responsabilidade ao sofrimento, parece psicologicamente mais fácil admitir que o sofrimento deriva das leis que a natureza impõe à condição humana; todo mundo, sob esse aspecto, está em pé de igualdade e o conhecimento das leis da natureza permite pre-

5 Remetemos, novamente, o leitor à nota 2, que esclarece essas abreviações. 
ver o que poderia acontecer. $\mathrm{O}$ acaso produz mais um sentimento de insegurança e de angústia diante do imprevisível. Quanto à própria atitude psicológica diante do sofrimento, ela parece regulada por dinamismos que cuidam de manter intacta a integridade da pessoa. Constata-se, com efeito, a recusa bastante sistemática de se deixar instalar numa posição masoquista ou na falta de sentido ou ainda num sentimento de impotência. É preferível enfrentar o sofrimento num enfrentamento (coping) positivo a reprimi-lo e negá-lo. Mesmo quando ele se revela inevitável, mais vale acolhê-lo com um sorriso, dizendo para si mesmo que outros são ainda mais infelizes; é preferível acreditar que se pode sair dele, e mesmo que se vai sair dele engrandecido, a aceitar passivamente ser vítima dele.

Quando se estimula a aproximação dessa questão do sofrimento humano com o campo religioso da vida de nossos sujeitos, ela se torna muito interativa e ocasiona representações muito diversas, que se mostram em relação direta com a configuração precisa da atitude religiosa das pessoas.

No campo religioso, a queixa do sofrimento se revela realmente polifônica e as vozes podem ser muito discordantes. O sofrimento pode suscitar a dúvida, como pode alimentar a confiança. Deus não é, em geral, reconhecido diretamente como responsável por ele, mas alguns não hesitam em bvantar-lhe a questão de sua implicação ou do sentido que ele próprio dá ao sofrimento. Como vimos, várias maneiras de levantar essa questão se correlacionaram com várias posições religiosas.

- Os mais distantes de uma fé integrada (os CDocc e os CDexp-) parecem adotar uma atitude desligada; quase excluem a referência religiosa da questão levantada pelo sofrimento.

- Os que são habitados pela dúvida, embora permanecendo apegados à fé em Deus criador (principalmente os CDreg), são os mais incisivos e os mais intolerantes frente a um Deus que permite que as leis da natureza sejam o que são.

- Os que crêem com toda confiança (particularmente os CCch-) tendem a pensar que Deus está próximo dos que sofrem e que ele os sustenta em sua busca do caminho a seguir para assumir positivamente a provação. 
Depois da análise de todas essas posições, constatamos que a posição que lhes tínhamos dado segundo os resultados no teste das orientações religiosas (intrínseca, de busca e extrínseca), guarda a mesma ordem decrescente de um subgrupo a outro, quando se trata de avaliar o grau de integração religiosa que pode receber a questão do sofrimento.

1. Os CCch- o integram com mais finura e positividade; eles são os únicos a poder captar o alcance de discursos teológicos que associam os sofrimentos do cristão aos do Cristo redentor, portanto, a dar um sentido religioso num segundo nível, sem interrogar a Deus acerca de sua responsabilidade de criador; eles são igualmente os únicos a poder compartilhar isso na oração, individualmente ou com a comunidade cristã. A experiência da adversidade, que é o sofrimento, tem por efeito aproximá-los de Deus e reforçar sua relação pessoal e sua fé.

2. Entre os três subgrupos do meio, os CDreg se mostram os mais desorientados pela contradição que experimentam entre o fato de que o sofrimento humano é inerente à existência e o fato de que se atribui a Deus ser criador das leis da natureza que regem essa existência. Como, para eles, conciliar a manutenção da crença em um Deus criador bom e o reconhecimento dessa falha dolorosa na condição humana, portanto, na criação? Essa dificuldade não é para eles uma simples questão de dissonância cognitiva. Eles a ressentem tanto mais fortemente quanto permanecem apegados a sua fé pessoal e mesmo se sentem aproximados de Deus pelo sofrimento e continuam rezando e levantando suas questões (eles são "busca+intrínsecos"). Eles estão como fixados na posição de Jó. Assim, certos discursos religiosos os decepcionam, como falar de uma vontade de Deus que permitiria o sofrimento ou colocaria o fiel à prova; eles pouco se sensibilizam com a empatia de um Deus que se poria do lado dos sofredores; mas guardam um mínimo de confiança no fato de que Deus pode dar sentido ao sofrimento e de que ele acredita que o homem é capaz de suportá-lo. É uma lógica de integração entre sofrimento e religião totalmente diferente da dos Ccch-. 
3. Os CCch+ e os CDexp+ não parecem viver a experiência do sofrimento tão dificilmente como os CDreg, do ponto de vista religioso, mesmo que estejam, também eles, na posição religiosa mediana.

Os primeiros se caracterizam, com efeito, por um engajamento religioso que permanece tanto mais facilmente confiante quanto mais é autônomo, e mesmo distante, em relação à Igreja; eles pegam muito mais o que lhes convém e não se deixam embaraçar em demasia pelas questões teológicas ou místicas um tanto difíceis. Sua fé poderia mudar no futuro menos, parece, para se aprofundar, do que para se adaptar às circunstâncias. O sofrimento toma seu lugar, positivamente, nesse contexto psicológico.

Os CDexp+ parecem encarar toda implicação religiosa de maneira menos ansiosa e em referência ao fato de que seu encontro com Deus é positivo e sua experiência religiosa fundada na confiança. Sua dúvida, por conseguinte, nunca é fundamental e sua interpretação dos discursos religiosos é toda pessoal, não dependente do consenso do grupo religioso ao qual estão muito pouco vinculados.

4. Enfim, nos dois subgrupos da outra extremidade da cadeia (CDocc e CDexp-), o enraizamento religioso permaneceu muito exterior: a dúvida é tanto mais fácil quando não é sustentada pela ancoragem de uma experiência religiosa positiva ou pelo treinamento de uma prática religiosa regular; essa dúvida tampouco incomoda muito, pois não há vinculação com o grupo religioso. De fato, neles, o sofrimento permanece bastante exterior à questão religiosa; eles estão bastante distantes de uma verdadeira relação de fé e não deixam seu sofrimento entrar nas superações propostas pelos discursos religiosos.

Como conclusão final, a experiência humana do sofrimento não deixa a atitude religiosa indiferente. Uma experiência como essa estimula a atitude religiosa em certos parâmetros da estrutura pessoal em que ela se encontra atualmente estabilizada. Afinal de contas, essa experiência constitui, ao menos, tanto uma ocasião de fazer progredir a vida de fé, quanto um motivo de renunciar à fé. 
Jaspard, J. M. (2004). Religious Significance of Suffering and Psychological Position in Faith. Psicologia USP, 15(3), 191-212.

\begin{abstract}
The psychological bond between the existencial experience of suffering and the position of the subject in relation to religious faith are studied. The investigation comprised 80 nurses, from both sexes, with various degrees of adherence to Christianism. The hypothesis was that these persons are impelled to structure for themselves a more or less stable, conscious or reflected attitude towards suffering. A questionnaire was elaborated including a question concerning suffering (dimensions, psychological aprehension, meaning), a question about the religious position (central or peripheric, certain or hesitant) and a question concerning the atribution of religious conotations to suffering. Results do not allow one to enunciate a homogeneous theory on the relation between religion and suffering, but the existence of singular configurations more or less stable and evolving, according to the religious attitude basic orientation, the merely human context of suffering and the religious contextualization of suffering.
\end{abstract}

Index terms: Suffering. Psychology and religion.

Recebido em 03.08.2004

Aceito em 24.11.2004 